\title{
Correspondence
}

\section{Putting into action the REGCM4.6 regional climate model for the study of climate change, variability and modeling over Central America and Mexico}

\author{
Jorge A. AMADOR ${ }^{1 *}$, Tercio AMBRIZZI ${ }^{2}$, Raymond W. ARRITT ${ }^{3}$, Christopher L. CASTRO $^{4}$, Tereza CAVAZOS $^{5}$, \\ Ruth CEREZO-MOTA ${ }^{6}$, Ramón FUENTES-FRANCO ${ }^{7}$, Filippo GIORGI ${ }^{8}$, Graziano GUILIANI ${ }^{8}$, Huikyo LEE ${ }^{9}$, \\ Matías MÉNDEZ-PÉREZ ${ }^{10}$ and Erick R. RIVERA ${ }^{1}$ \\ 1 Center for Geophysical Research and School of Physics, University of Costa Rica, Costa Rica \\ ${ }^{2}$ Department of Atmospheric Sciences, University of Sao Paulo, Brazil \\ 3 Department of Agronomy, Iowa State University, Ames, Iowa \\ ${ }^{4}$ Department of Hydrology and Atmospheric Sciences, University of Arizona, Tucson, Arizona \\ 5 Departamento de Oceanografía Física, Centro de Investigación Cientifica y Educación Superior de Ensenada \\ (CICESE), Baja California, México \\ ${ }^{6}$ Laboratorio de Ingeniería y Procesos Costeros, Instituto de Ingeniería, Universidad Nacional Autónoma de México, \\ Yucatán, México \\ ${ }^{7}$ Rossby Centre, Sweden \\ ${ }^{8}$ International Centre for Theoretical Physics, Trieste, Italy \\ 9 Jet Propulsion Laboratory, California Institute of Technology, Pasadena, California \\ ${ }^{10}$ Licenciatura en Ciencias Atmosféricas, Universidad Veracruzana, Veracruz, México \\ * Corresponding author; email: jorge.amador@ucr.ac.cr
}

Received: October 12, 2017; accepted: February 23, 2018

\section{SECOND WORKSHOP ON CLIMATE CHANGE, VARIABILITY AND MODELING OVER CENTRAL AMERICA AND MEXICO}

\begin{abstract}
What: International experts and attendees from several countries of Central America, Mexico, the Caribbean (CAM), and South America (SA) met to discuss regional issues on climate variability and climate change to learn the use of the non-hydrostatic version of the International Center for Theoretical Physics (ICTP) RegCM4.6 model, and to establish a regional modeling scientific community for understanding the physics of climate processes and the generation of regional climate change scenarios.
\end{abstract}

When: 14-18 November 2016.

Where: Center for Geophysical Research (CIGEFI in Spanish) and School of Physics, University of Costa Rica (UCR), San José, Costa Rica. 


\section{Rationale}

The CAM region is very vulnerable to extreme climatic events that cause socio-economic and natural disasters (Amador 2011; Cavazos 2015). Specifically, Central America is a "hot spot" for climate change impacts (Giorgi, 2006), being one of the most susceptible regions in the world to climate change (a decrease in precipitation and an increase in precipitation variability, as measured by the coefficient of variation). National and international assessments of current and future climate changes are providing increasingly important scientific information crucial for economic and political decision-making to respond to a changing climate. A core element of these assessments are numerical model projections that not only provide a foretelling of physical indicators of future climate but also indirectly supply information on societal impacts. Despite recent improvements, coarse-resolution global climate models have a relatively poor representation of the main climate features of the CAM region (Giorgi and Mearns 1999; Nakaegawa et al. 2014). Therefore, the use of limited area regional climate models (RCMs) at high spatial resolution is an important complimentary tool to approach the problem of modeling regional climate variability and change. Since the Coordinated Regional Downscaling Experiment (CORDEX, http:// www.cordex.org/, Giorgi and Gutowski, 2015; Gutowski et al. 2016) vision is to advance and coordinate the science and application of regional climate downscaling through global partnerships, the organizers of the second workshop on climate change, variability and modeling over CAM envisaged this event as an opportunity for the region to become more engaged in CORDEX activities.

The main purpose of the workshop was to provide extensive sessions focused on the physics of RCMs and on the implementation of techniques to carry out high-resolution analyses of local climate phenomena, their variability and future changes in the CAM area. A related purpose was to build regional capacity for applying state of the art RCMs and analysis in this region.

The workshop participants had the opportunity to implement and use the latest version of the ICTPRCM (the RegCM4.6), enhancing their understanding of the physics and dynamics of regional climate processes over the CAM area. It is expected that finer resolution climate change projections generated by this approach may have a positive effect in the prevention and mitigation of climate impacts in the region.

The workshop was organized with lectures, demonstrations of special software implementations and laboratory sessions, which provided a background on climate studies focused on CAM.

The ability of RCMs to represent physical processes and related uncertainty was also addressed in the lectures due to their relevance in climate variability and change studies. Giving continuity to the First Workshop on Climate Change, Variability and Modeling focused in this region organized by ICTP and CICESE in Ensenada, Mexico in 2014, one of the specific goals of the second workshop was to consolidate the community of model users in CAM, especially those of the RegCM4 system, under the CORDEX framework. A total of 29 participants attended the workshop, many of them with proven experience in handling climate data, and with a particular interest in starting to use the RegCM4.6 for regional climate studies. An internationally recognized group of invited scientists delivered presentations and promoted discussions on the theory of climate dynamics and climate change. ICTP experts introduced and installed the non-hydrostatic version (the RegCM4.6) for use by the participants.

The poster of the event can be seen at http://indico. ictp.it/event/7621, and the agenda and the invited speakers' presentations are available emailing the corresponding author.

\section{Highlights of the sessions}

Mornings were devoted to theoretical lectures on climate variability and climate change, presentations of studies on the North American Monsoon (NAM), climate features of the CAM region, such as the Mid-Summer Drought (MSD, Magaña et al. 1999), the Caribbean Low Level Jet (CLLJ, Amador 1998, 2008), Tropical Cyclones (Fuentes-Franco et al. 2016), a review of the advances in regional climate modeling in the CAM region, and tutorial sessions on the use of the RegCM4.6 model. Afternoons were dedicated to hands-on laboratory sessions running the RegCM4.6 model on the Tsaheva computational cluster of CIGEFI-UCR. The laboratory session participants formed ten working groups to develop a set of preliminary 
regional climate projects and presented their projects on the last day of the Workshop.

The morning session on Monday 14 November began with presentations on the theory and use of RCMs, with an introduction to the RegCM4.6 model, its computational structure, and modular system. In the evening, there was an open session for the attendees to introduce and discuss CORDEX objectives for the CAM region and the capability to integrate them into future CORDEX scenarios and the next Intergovernmental Panel on Climate Change (IPCC) report. The second day offered an update on regional modeling studies highlighting the importance of focusing on physical processes that dominate the region (e.g., CLLJ, droughts, extreme events, NAM, tropical cyclones, land-sea thermal contrasts), the effect of domain size in the description of features of the NAM system, and the evaluation of changes in extreme events during the NAM season (Cerezo-Mota et al. 2016) using convection-permitting regional climate modeling (Castro et al. 2015). As a way to motivate the investigation of model biases and the use of climate validation tools, the RCM Evaluation System (RCMES) was presented in a tutorial session (https://rcmes.jpl.nasa.gov/, Mattmann et al., 2014). In the afternoon, a CORDEX executive session was organized to explore actions for regional institutions to contribute and prepare products useful for the next IPCC reports $\left(1.5^{\circ} \mathrm{C}\right.$ and $\left.\mathrm{AR} 6\right)$.

On Wednesday 16th the Workshop attendees had the opportunity to visit the Irazú Volcano (3482 masl) some $40 \mathrm{~km}$ west of the UCR. Thursday 17 started with presentations regarding the MSD nature, the sensitivity of precipitation and atmospheric low-level circulation patterns (CLLJ) to domain size in RegCM4.4.5, and studies on intra-seasonal precipitation variability and land-atmosphere coupling in the CAM region. On Friday, the last day of the workshop, a presentation was given on the sensitivity of tropical cyclones to convective schemes and ocean flux parameterizations over the eastern tropical Pacific and tropical North Atlantic basins using RegCM4 model (Fuentes-Franco et al. 2016). Some applications to climate analysis, forecasting, and future climate projections for SA were also presented. In particular, emphasis was given on the simulation of extratropical cyclones over the South Atlantic Ocean and how their intensity and location can be modified under a greenhouse gas warming.
Extreme precipitation events simulated by both RegCM3 and RegCM4 over SA demonstrated the usefulness of dynamical downscaling in a representation of key atmospheric processes in the region. Finally, the presentations of regional projects from the participants wrapped up the event.

\section{Remarks}

The contribution and support of several international organizations permitted to continue the process of developing and strengthening the skills, processes, and resources of the climate modeling community in the CAM and SA regions. The Workshop showed abundant cases of expertise in the knowledge of climate and climate variability processes at regional level. Although the simulation results from the RegCM model were highlighted, the workshop also generated a rich environment for the comparison of results of different RCMs, and stressed the vision of the need for an increased collaboration among countries in the region. The participants, representing undergraduate, and graduate programs from 11 countries, were completely supported by local or international funds, allowing a very good degree of knowledge exchange in climate related issues.

\section{Acknowledgements}

The organizers greatly appreciate the generous contributions of the UCR and the financial and scientific support from the ICTP. Thanks are also due to the National Academy of Sciences of Costa Rica, the Costa Rica Ministry of Science, Technology and Telecommunications (FI-0015-16), the Costa Rica National Council for Science and Technology, the Center for Mexican Studies of the National Autonomous University of Mexico at UCR, and the Japan International Cooperation Agency. Thanks to Hugo Hidalgo from CIGEFI for comments to an earlier version of this manuscript. To Pandora Melchose from ICTP, Alejandra Montero and her staff from CIGEFI for their excellent service in the logistics. The workshop partially benefited from local grants UCR-VI-805-B0-065, A8-606, B0-130, A9-224, A7002, B0-402, B3-600, B4-227, B5-296, and 808-A9180. Participation by RWA was supported in part by the USDA National Institute of Food and Agriculture. 


\section{References}

Amador J., 1998. A climatic feature of the tropical Americas: The trade wind easterly jet. Top. Meteor. Ocean. 5, 91-102.

Amador J.A., 2008. The Intra-Americas Seas Low-Level Jet (IALLJ): Overview and future research. Trends and Directions in Climate Research (Gimeno L., García R. and Trigo R., Ed.). Ann. N. Y. Acad. Sci. 1146, 153188. DOI: $10.1196 /$ annals. 1446.012

Amador J.A., 2011. Socio-economic impacts associated with meteorological systems and tropical cyclones in Central America in 2010. In: State of the climate 2010 (Blunden J., Arndt D.S. and Baringer M.O., Eds.). Bull. Amer. Met. Soc. 92(6), S184-S189.

Castro C.L., Chang H.I., Luong T.M., Lahmersm T., Jares M. and Mazon J., 2015. Evaluating changes in extreme weather during the North American Monsoon in the Southwest US using high resolution, convective-permitting regional atmospheric modeling. AGU Fall Meeting Abstracts.

Cavazos T. (Ed.), 2015. Conviviendo con la naturaleza: El problema de los desastres asociados a fenómenos hidro-meteorológicos y climáticos en México. REDESClim. Ediciones ILCSA, Mexico, 143 pp. Available at: http://usuario.cicese.mx/ tcavazos/pdf/T_Cavazos_ Libro_REDESClim_2015.pdf

Fuentes-Franco R., Giorgi F., Coppola E. and Zimmermann K., 2016. Sensitivity of tropical cyclones to resolution, convection scheme and ocean flux parameterization over Eastern Tropical Pacific and Tropical North Atlantic Oceans in the RegCM4 model. Clim. Dynam. 49, 547-561. DOI: 10.1007/s00382-016-3357-3

Cerezo-Mota R., Cavazos T., Arritt R., Torres-Alavez A., Sieck K., Nikulin G., Moufouma-Okia W. and Salinas A., 2016. CORDEX-NA: factors inducing dry/wet years on the North American Monsoon region. Int. J. Climatol. 36, 824-836. DOI: 10.1002/joc.4385
Giorgi F. and Mearns L.O., 1999. Introduction to special section: Regional climate modeling revisited. J. Geophys. Res. 104, 6335-6352. DOI: 10.1029/98JD02072 Giorgi F., 2006. Climate change hot-spots. Geophys. Res. Lett., 33, L08707. DOI: $10.1029 / 2006$ GL025734.

Giorgi F. and Gutowski W.J., 2015. Regional dynamical downscaling and the CORDEX initiative. Annu. Rev. Env. Resour. 40, 467-490.

DOI: 10.1146/annurev-environ-102014-021217

Gutowski W.J., Giorgi F., Timbal B., Frigon A., Jacob D., Kang H.-S., Krishnan R., Lee B., Lennard C., Nikulin G., O'Rourke E., Rixen M., Solman S., Stephenson T. and Tangang F., 2016. WCRP Coordinated Regional Downscaling Experiment (CORDEX): A diagnostic MIP for CMIP6. Geosci. Model Dev. 9, 4087-4095. DOI: $10.5194 /$ gmd-9-4087-2016

Magaña V., Amador J.A. and Medina S., 1999. The Mid-Summer Drought over Mexico and Central America. J. Climate 12, 1577-1588.

DOI: 10.1175/1520-0442(1999)012<1577:TMDOMA $>2.0 . \mathrm{CO} ; 2$

Mattmann C.A., Waliser D., Kim J., Goodale C., Hart A., Ramirez P., Crichton D., Zimdars P., Boustani M., Lee K., Loikith P., Whitehall K., Jack C. and Hewitson B., 2014. Cloud computing and virtualization within the regional climate model and evaluation system. Earth Sci. Inform. 7, 1-12.

DOI: $10.1007 / \mathrm{s} 12145-013-0126-2$

Nakaegawa T., Kitoh A., Murakami H. and Kusunoki S., 2014. Annual maximum 5-day rainfall total and maximum number of consecutive dry days over Central America and the Caribbean in the late twenty-first century projected by an atmospheric general circulation model with three different horizontal resolutions. Theor Appl Climatol, 116, 155-168. DOI:10.1007/s00704-013-0934-9 